\title{
Recomendaciones de manejo de la Gripe A en la Unidad de Cuidados Críticos.
}

Charco Roca LM, Jiménez Vizuete JM

\section{Hospital General Universitario de Albacete.}

\begin{abstract}
Resumen
La infección por Gripe A es una enfermedad grave, siendo una causa principal de insuficiencia respiratoria aguda durante las estaciones epidémicas. Algunos pacientes desarrollan complicaciones graves, con necesidad de ventilación mecánica y medidas de soporte de otros fracasos orgánicos precisando ingreso en Unidades de Cuidados Críticos. El conocimiento de las complicaciones y adecuado manejo de estos pacientes disminuye la morbimortalidad asociada a esta infección. Este documento proporciona pautas de manejo extraídas de documentos de consenso con el fin de sintetizar el conocimiento actual sobre el manejo del paciente grave con Gripe A.
\end{abstract}

\section{Introducción}

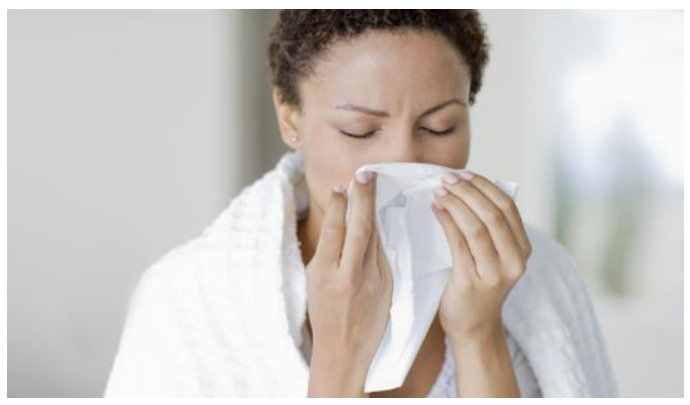

La infección por Gripe A es una enfermedad grave, siendo una causa principal de insuficiencia respiratoria aguda durante las estaciones epidémicas. Algunos pacientes desarrollan complicaciones graves, con necesidad de ventilación mecánica y medidas de soporte de otros fracasos orgánicos precisando ingreso en Unidades de Cuidados Críticos. El conocimiento de las complicaciones y adecuado manejo de estos pacientes disminuye la morbimortalidad asociada a esta infección. Este documento proporciona pautas de manejo extraídas de documentos de consenso con el fin de sintetizar el conocimiento actual sobre el manejo del paciente grave con Gripe A.

La aparición del brote por el virus de la gripe A/H1N1 en la pandemia del 2009 supuso un reto sanitario en el que las unidades de Cuidados Críticos se vieron implicadas. Los afectados pueden desarrollar complicaciones graves, con necesidad de ventilación mecánica $\mathrm{y}$ medidas de soporte de otros fracasos orgánicos.

Si bien la mayoría de los casos de gripe $\mathrm{A} / \mathrm{H} 1 \mathrm{~N} 1$ tienen un curso clínico benigno, un grupo significativo de infectados precisa ingreso hospitalario $(0,3-0,5 \%)$ y eventual tratamiento en Cuidados Críticos (10-30\%). En los registros españoles, la mortalidad de los pacientes que precisaron ingreso en Cuidados Críticos entre los años 2009 a 2015 fue del 22-25\%, mostrándose un aumento de la misma con la edad. Las presentes recomendaciones han sido extraídas de una selección de documentos de consenso y artículos de revisión publicados durante la última década y resumen las directrices de 
manejo de los enfermos ingresados por Gripe A en las unidades de Cuidados Críticos.

\section{Recomendaciones}

1. La realización de una prueba diagnóstica lo antes posible, a todos los pacientes con fiebre y cuadro gripal que requirieren hospitalización.

El diagnóstico de gripe es fundamentalmente clínico, sobre todo durante los picos de la gripe estacional. La presentación clínica de fiebre y tos en las $48 \mathrm{~h}$ previas al inicio del resto de los síntomas respiratorios tiene un valor predictivo positivo muy elevado, con buena correlación con los resultados de la reacción en cadena de la polimerasa en transcripción reversa (rt-PCR). Las muestras para confirmar la etiología por $\mathrm{A} / \mathrm{H} 1 \mathrm{~N} 1$ deben ser tomadas tan pronto como se sospeche clínicamente en todo paciente que requiera hospitalización. Se recomienda tomarlas de distintos puntos del tracto respiratorio (endotraqueal en pacientes intubados) $\mathrm{y}$ preferiblemente mediante aspirado.

Para la monitorización del aclaramiento viral se recomienda solicitar rt-PCR a los 7-10 días de inicio del tratamiento con el fin de adecuar las medidas de aislamiento.

2. La administración de oseltamivir de manera precoz. Los fármacos antivirales disponibles en la actualidad incluyen inhibidores de la neuraminidasa (INAs) (p. ej., oseltamivir oral, zanamivir inhalado, y peramivir intravenoso); inhibidores de la endonucleasa cap-dependiente de los virus gripales (baloxavir marboxil); y adamantanos (amantadina y rimantadina). NAIs y baloxavir tienen actividad frente a virus de la gripe A y B. Los adamantanos solo tienen actividad contra la influenza y no se recomiendan para su tratamiento debido a la resistencia generalizada de las actuales cepas estacionales. A falta de estudios aleatorios y controlados sobre el efecto del tratamiento antiviral en el enfermo crítico con infección severa por $\mathrm{A} / \mathrm{H} 1 \mathrm{~N} 1$, la experiencia acumulada permite recomendar la administración de oseltamivir (inhibidor de la neuraminidasa) en dosis de 75 mg vía oral cada $12 \mathrm{~h}$ durante al menos 7 días. El antiviral precisa ajuste posológico para insuficiencia renal $\mathrm{y}$ podría aumentarse la dosis al doble (150 mg/12h), especialmente en obesos con índice de masa corporal (IMC) mayor de 30 $\mathrm{Kg} / \mathrm{m} 2$, debido al mayor volumen de distribución y en casos graves. Deben considerarse ciclos de mayor duración en pacientes inmunocomprometidos y cuando se desarrolla síndrome de distrés respiratorio agudo (SDRA). El tratamiento antiviral administrado en menos de 48 horas desde el inicio de los síntomas disminuye la mortalidad y es considerado un estándar de calidad en el cuidado de estos pacientes. Resulta muy interesante el estudio de la modificación de la respuesta antiviral del huésped a la infección por el virus de la influenza. La combinación triple de oseltamivir, claritromicina y naproxeno para la influenza grave tiene un estudio que respalda su uso. Los estudios 
confirmatorios serían de gran interés por lo que se está investigando con una variedad de agentes inmunomoduladores, entre los que se incluyen el celecoxib, las estatinas, la Nacetilcisteína, el etanercept, la pioglitazona, los macrólidos $\mathrm{y}$ determinados interferones.

3. La cobertura antibiótica empírica para una coinfección bacteriana.

Se define como coinfección respiratoria adquirida en la comunidad o relacionada con la asistencia sanitaria cualquier infección bacteriana respiratoria diagnosticada en un afectado de gripe $\mathrm{A} / \mathrm{H} 1 \mathrm{~N} 1$ dentro de las primeras $48 \quad \mathrm{~h}$ de hospitalización. Pasadas dichas $48 \mathrm{~h}$ la coinfección bacteriana se consideraría nosocomial. En hasta un 20\% de los casos de gripe A se detecta coinfección bacteriana. Los patógenos más frecuentemente aislados son Streptococcus pneumoniae y Staphylococcus aureus. Se recomienda por tanto iniciar tratamiento empírico precoz, por ejemplo con un betalactámico más un macrólido y decidir en función del curso clínico o los aislamientos microbiológicos su retirada 0 escalada. En los últimos años, cada vez más informes describen la aspergilosis invasiva (AI) como una complicación frecuente incluso en pacientes no inmunodeprimidos. La morbilidad y mortalidad de la AI como coinfección dentro de un cuadro de $\mathrm{A} / \mathrm{H} 1 \mathrm{~N} 1$ es alta, y en la mayoría de ellos, el inicio ocurre temprano después de la admisión en la unidad de Cuidados Críticos. El lavado broncoalveolar debe obtener muestras del tracto respiratorio inferior y en caso de pruebas positivas para Aspergillus, la tomografía computerizada de tórax es la modalidad de imagen de elección. Ante la sospecha de AI debe iniciarse tratamiento con un azol (voriconazol, isavuconazol).

4. La no utilización de esteroides. El uso de corticoides a dosis bajas o moderadas fue propuesto para disminuir las secuelas o la progresión de la lesión pulmonar aguda inducida por el virus. Las directrices para el tratamiento de la infección humana por el virus pandémico A/H1N1 coinciden en recomendar que la terapia con corticosteroides no debe usarse de forma rutinaria, dada la ausencia de evidencia científica que justifique su beneficio.

Las dosis bajas pueden ser consideradas en pacientes con shock séptico que requieren vasopresores y ante sospecha de insuficiencia suprarrenal.

5. Considerar la ventilación mecánica invasiva (VMI) en pacientes que requieran soporte ventilatorio como técnica de elección.

La afectación respiratoria producida por el virus de la gripe A tiene 5 formas principales de presentación: 1) neumonitis viral o neumonía viral primaria con SDRA grave; 2) episodios de reagudización asmática; 3) episodios de reagudización en pacientes con enfermedad pulmonar obstructiva crónica (EPOC); 4) coinfección bacteriana asociada a infección viral y 5) episodios de bronquiolitis en pacientes pediátricos.

Ante la elevada tasa de fracaso de la ventilación mecánica no invasiva (VMNI) encontrada en 
los estudios, y la asociación del fracaso con un aumento de mortalidad se puede afirmar que no pueda ser considerada una técnica de elección en los casos que desarrollen SDRA. Hay un consenso generalizado en el uso de «estrategias ventilatorias protectoras del pulmón» cuando se precisa ventilación mecánica invasiva (tabla 2), combinadas con el empleo de medidas de rescate de la hipoxemia como la ventilación en prono, la relajación muscular y las maniobras de reclutamiento.

6. La detección precoz y el tratamiento de soporte de las complicaciones.

Las complicaciones asociadas a la infección por gripe A son múltiples y las más frecuentemente observadas han sido el SDRA relacionado con el desarrollo de neumonía viral primaria, la inestabilidad hemodinámica, el fallo renal agudo $y$ el fracaso multiorgánico.

La oxigenación con membrana extracorpórea (ECMO) es una medida de soporte y ha sido utilizada con frecuencia para la gripe $\mathrm{A}$ en situaciones de hipoxemia refractaria, con resultados clínicos dispares según los estudios hasta la fecha. El fin de esta técnica no es curativo pero con su uso se consigue ganar tiempo para continuar con el diagnóstico, la aplicación de medidas terapéuticas y la recuperación de la causa inicial que condujo al cuadro. Con el nivel de evidencia existente, lo invasivo de la técnica y sus complicaciones potenciales, la ECMO se debe considerar un tratamiento de rescate cuando han fracasado medidas terapéuticas menos invasivas.

7. La vacunación antigripal a toda la población con riesgo. El objetivo de las campañas de vacunación es disminuir la morbimortalidad en grupos de riesgo y reducir el impacto de esta enfermedad en la comunidad. La efectividad de las vacunas frente a enfermedad confirmada por laboratorio varía entre los diferentes grupos de edad $(70 \%$ al $38 \%)$ pero es importante tener en cuenta que, aunque se pueda adquirir la infección, la enfermedad será con mucha probabilidad menos grave si ha habido vacunación anterior.

\section{Conclusiones}

La infección por Gripe A es una enfermedad grave, siendo una causa principal de insuficiencia respiratoria aguda durante las estaciones epidémicas. Entre los factores de riesgo asociados al desarrollo de enfermedad grave e ingreso en Cuidados Críticos se incluyen la patología respiratoria y la obesidad mórbida. Los pacientes afectados por Gripe A estacional que ingresan en una Unidad de Críticos tienen hasta un $20 \%$ de mortalidad y se presentarán con neumonía primaria más del $70 \%$ de las ocasiones.

La administración de oseltamivir dentro de las $48 \mathrm{~h}$ del inicio del cuadro y la vacunación representan las principales estrategias orientadas a mejorar la supervivencia.

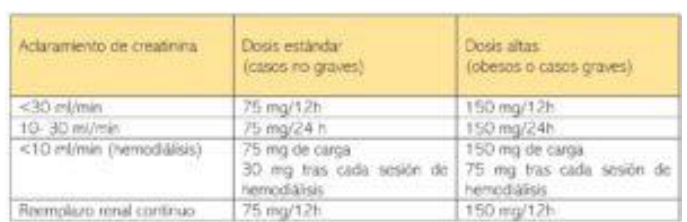

Tabla 1: Ajuste posológico de oseltamivir. 


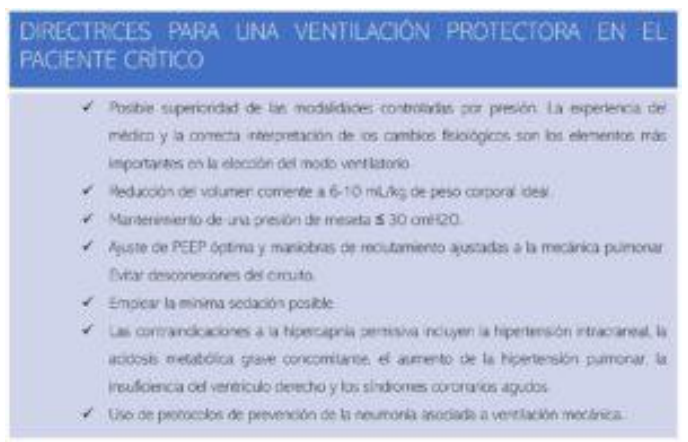

Tabla 2: Directrices para una ventilación protectora.

\section{Lecturas recomendadas}

1. Harper SA, Bradley JS, Englund JA, File TM, Gravenstein S, Hayden FG, et al., Expert Panel of the Infectious Diseases Society of America. Seasonal influenza in adults and childrendiagnosis, treatment, chemoprophylaxis, and institutional outbreak management: clinical practice guidelines of the Infectious Diseases Society of America. Clin Infect Dis. 2009;48:1003-32. (PubMed)

2. Rodríguez, L. Álvarez-Rocha, J.M. Sirvent, R. Zaragoza, M. Nieto, et al. Recomendaciones del Grupo de Trabajo Enfermedades Infecciosas (GTEI) de la Sociedad Española de Medicina Intensiva, Crítica y Unidades Coronarias (SEMICYUC) y el Grupo de Estudio de Infecciones en el Paciente Crítico (GEIPC) de la Sociedad Española de Enfermedades Infecciosas y Microbiología clínica (SEIMC) para el diagnóstico $y$ tratamiento de la gripe $\mathrm{A} / \mathrm{H} 1 \mathrm{~N} 1$ en pacientes adultos graves hospitalizados en las Unidades de Cuidados Intensivos. Med Intensiva. 2012;36(2):103-137. (HTML)

3. Sarda C, Palma P, Rello J. Severe influenza: overview in critically ill patients. Curr Opin Crit Care 2019, 25:449-457. (PubMed)

4. Koehler P, Bassetti M, Kochanek M, Shimabukuro-Vornhagen A, Cornely OA. Intensive Care management of influenza-associated pulmonary aspergillosis. Clin Microbiol Infect. 2019 Dec;25(12):1501-1509. (PubMed)

5. Zarogoulidis P, Papanas N, Kioumis I, Chatzaki E, Maltezos E, Zarogoulidis $\mathrm{K}$. Macrolides: from in vitro antiinflammatory and immunomodulatory properties to clinical practice in respiratory diseases. Eur J Clin Pharmacol. 2012 May; 68(5):479-503 (PubMed)

6. Chow E, Doyle J.D, Uyeki T.M. Influenza virus-related critical illness: prevention, diagnosis, treatment. Critical Care 2019; 23: 214. (ubMed)

Correspondencia al autor

Luisa María Charco Roca

luisacharco@gmail.com

FEA Anestesiología y Reanimación.

Hospital General Universitario de Albacete.

Aceptado para el blog en marzo de 2020 